\title{
Numerical constraints and feedback control of double-strand breaks in mouse meiosis
}

\author{
Liisa Kauppi, ${ }^{1,2,3}$ Marco Barchi, ${ }^{4,5,8}$ Julian Lange, ${ }^{1,8}$ Frédéric Baudat, ${ }^{4,6}$ Maria Jasin,, 4 \\ and Scott Keeney ${ }^{1,7,9}$

\begin{abstract}
${ }^{1}$ Molecular Biology Program, Memorial Sloan-Kettering Cancer Center, New York, New York 10065, USA; ${ }^{2}$ Research Programs Unit (Genome-Scale Biology), ${ }^{3}$ Institute of Biomedicine (Biochemistry and Developmental Biology), University of Helsinki, 10065, USA; ${ }^{5}$ Department of Biomedicine and Prevention, Section of Anatomy, University of Rome Tor Vergata, 00133 Rome, Italy; ${ }^{6}$ Institute of Human Genetics, UPR1142/Centre National de la Recherche Scientifique (CNRS), 34936 Montpellier CEDEX
\end{abstract} \\ Helsinki FIN-00014, Finland; ${ }^{4}$ Developmental Biology Program, Memorial Sloan-Kettering Cancer Center, New York, New York \\ 5, France; ${ }^{7}$ Howard Hughes Medical Institute, Memorial Sloan-Kettering Cancer Center, New York, New York 10065, USA
}

Different organisms display widely different numbers of the programmed double-strand breaks (DSBs) that initiate meiotic recombination (e.g., hundreds per meiocyte in mice and humans vs. dozens in nematodes), but little is known about what drives these species-specific DSB set points or the regulatory pathways that control them. Here we examine male mice with a lowered dosage of SPO11, the meiotic DSB catalyst, to gain insight into the effect of reduced DSB numbers on mammalian chromosome dynamics. An approximately twofold DSB reduction was associated with the reduced ability of homologs to synapse along their lengths, provoking prophase arrest and, ultimately, sterility. In many spermatocytes, chromosome subsets displayed a mix of synaptic failure and synapsis with both homologous and nonhomologous partners ("chromosome tangles"). The $\mathbf{X}$ chromosome was nearly always involved in tangles, and small autosomes were involved more often than large ones. We conclude that homolog pairing requirements dictate DSB set points during meiosis. Importantly, our results reveal that karyotype is a key factor: Smaller autosomes and heteromorphic sex chromosomes become weak links when DSBs are reduced below a critical threshold. Unexpectedly, unsynapsed chromosome segments trapped in tangles displayed an elevated density of DSB markers later in meiotic prophase. The unsynapsed portion of the $\mathbf{X}$ chromosome in wild-type males also showed evidence that DSB numbers increased as prophase progressed. These findings point to the existence of a feedback mechanism that links DSB number and distribution with interhomolog interactions.

[Keywords: DNA double-strand break; homologous pairing; meiosis; recombination; spermatogenesis; Spo11; synaptonemal complex]

Supplemental material is available for this article.

Received January 9, 2013; revised version accepted March 27, 2013.

During meiosis, the specialized cell division that generates haploid gametes for sexual reproduction, homologous chromosomes engage each other at multiple positions along their lengths via recombination initiated by DNA double-strand breaks (DSBs) (Hunter 2007). Recombination promotes homolog pairing and accurate chromosome segregation, but DSBs are potentially lethal genomic insults if repaired incorrectly or not at all. Thus, a fundamental question in chromosome biology is how meiotic cells control DSB formation to foster its essential functions but minimize untoward effects.

\footnotetext{
${ }^{8}$ These authors contributed equally to this work.

${ }^{9}$ Corresponding authors

E-mail s-keeney@ski.mskcc.org

E-mail m-jasin@ski.mskcc.org

Article published online ahead of print. Article and publication date are

online at http://www.genesdev.org/cgi/doi/10.1101/gad.213652.113.
}

The simplified sequence of meiotic chromosome dynamics in many organisms can be summarized as follows: Meiotic DSBs catalyzed by SPO11 protein are processed into $3^{\prime}$ ssDNA tails, which are required for homology search, leading to stable interhomolog interactions and, subsequently, the formation of the synaptonemal complex (SC), a zipper-like proteinaceous structure between homologous chromosomes (e.g., see Zickler 1977; Rasmussen and Holm 1978; Maguire 1984; Zickler and Kleckner 1999; Storlazzi et al. 2010). Multiple interstitial recombination events are needed for progressive stabilization of homologous interactions and synapsis (e.g., see Smithies and Powers 1986; Weiner and Kleckner 1994; Kleckner 1995; Peoples-Holst and Burgess 2005), as inferred primarily from budding yeast, filamentous fungi, and plants (Albini and Jones 1984; von Wettstein et al. 1984; Tesse et al. 2003; Peoples-Holst and Burgess 2005). 
In mice, homolog synapsis is recombination-dependent; in the absence of DSBs or when certain recombination proteins are missing, SC formation is reduced, and SC that does form is frequently between nonhomologous chromosomes (Pittman et al. 1998; de Vries et al. 1999; Baudat et al. 2000; Romanienko and Camerini-Otero 2000; Petukhova et al. 2003).

Although DSB numbers vary significantly from cell to cell (Chen et al. 2008; Cole et al. 2012), much greater intrinsic difference is seen when comparing different organisms, implying the existence of species-specific set points for DSB numbers. Species with recombinationindependent pairing (Drosophila and nematodes) form relatively few DSBs (Jang et al. 2003; Mets and Meyer 2009; Rosu et al. 2011). In contrast, fungi, plants, and mammals, where recombination is required for stable pairing, make many more DSBs (e.g., Terasawa et al. 1995; Plug et al. 1996; Barlow et al. 1997; Lenzi et al. 2005; Sanchez-Moran et al. 2007; Mancera et al. 2008; Roig et al. 2010; Storlazzi et al. 2010). For example, mouse spermatocytes are estimated to make $\sim 200-250$ DSBs on average, based on numbers of chromosome-associated foci of the strand exchange proteins RAD51 and DMC1. Of this number, only approximately one-tenth is matured into crossovers; analysis of individual recombination hot spots suggests that a large fraction of the remaining DSBs mature into noncrossovers (Cole et al. 2010; F Baudat and B de Massy, unpubl.; E de Boer, M Jasin and S Keeney, unpubl.), although the possibility of substantial sister chromatid recombination, which would not contribute to homolog pairing, has not been ruled out. The correlation of global DSB numbers with recombination dependence of pairing suggests that homolog pairing-instead of simply the requirement for crossovers-imposes a critical constraint on the minimum DSB number needed for successful meiosis.

Empirical support for this hypothesis comes from budding yeast and Sordaria macrospora, in which reduced DSB levels cause pairing and/or synapsis defects (Davis et al. 2001; Tesse et al. 2003; Henderson and Keeney 2004). However, the substantial differences in genome size and complexity between these fungi and mammals make it difficult to extrapolate from one organism to another. Within a given species, chromosome sizes vary greatly (in humans, for example, the smallest chromosome is approximately one-fifth the size of the largest chromosome), and genomes of male mammals are faced with the challenge of pairing the largely nonhomologous $\mathrm{X}$ and $\mathrm{Y}$ chromosomes. It is not known whether and how these two prominent features-chromosome size and the presence of heteromorphic sex chromosomes-affect minimum DSB requirements.

Separate but related to the question of why cells make a certain number of DSBs is how they ensure that the correct number is made. The DSB-forming machinery appears to be in excess over the DSBs actually formed (Neale et al. 2005; Milman et al. 2009; Lange et al. 2011), implying the existence of feedback mechanisms that influence SPO11 activity (Joyce et al. 2011; Lange et al. 2011; Zhang et al. 2011). However, it has been unclear how such feedback is integrated with meiotic chromosome dynamics.
To explore these facets of DSB control, we analyzed chromosome behaviors in mice that display an approximately twofold reduced meiotic DSB level. Our findings provide evidence that minimum DSB numbers are dictated principally by the pairing/synapsis requirements of the most vulnerable (smallest) chromosomes and that the presence of heteromorphic sex chromosomes affects the susceptibility of autosomes to pairing defects. Furthermore, we propose the presence of feedback mechanisms that integrate synapsis with the capacity of chromosomes to continue making DSBs.

\section{Results}

\section{$\mathrm{Tg}(\text { Spo11 } \beta)^{+/-}$males form fewer DSBS}

Spo11 knockout alleles, alone or in combination with a transgene, have provided an allelic series that allows experimental manipulation of SPO11 protein and DSB levels (summarized in Supplemental Table 1). Spo11 ${ }^{+/-}$ male mice have $\sim 50 \%$ the level of SPO11 protein compared with Spo11 $1^{+/+}$mice but only, at most, a 20\%-30\% reduced level of DSBs (Bellani et al. 2010; Cole et al. 2012). Mice are able to cope with this difference, as chromosome synapsis and crossing over are normal (Cole et al. 2012). To attempt to further reduce SPO11 levels, we generated mice in which the protein is expressed exclusively from a hemizygous $S p o 11 \beta$ transgene locus, henceforth referred to as $\operatorname{Tg}(\operatorname{Spo11\beta })^{+/-}$. $S p o 11 \beta$ is one of two major splicing isoforms (with Spo11 $\alpha$ ) (Keeney et al. 1999; Romanienko and CameriniOtero 1999); expression of the isoforms is developmentally regulated, with SPO11 $\beta$ expressed earlier, at the time that most DSBs are made (Romanienko and CameriniOtero 2000; Bellani et al. 2010; Kauppi et al. 2011). We showed previously that males homozygous for the Spo11 $\beta$ transgene display at least wild-type levels of autosomal DSBs and normal autosomal pairing, synapsis, and recombination; the only detectable defect in these mice was reduced XY recombination (Kauppi et al. 2011), possibly caused by the absence of the later SPO11 $\alpha$ isoform.

To examine the effect of reduced $S p o 11 \beta$ transgene dosage on SPO11 protein levels, we used 14-d-postpartum (dpp) juvenile mice in which the cellular composition of the testis is not yet affected by apoptosis that eliminates defective spermatocytes (see below). As expected, both $S p o 11^{+/-}$and $T g(\operatorname{Spo} 11 \beta)^{+/-}$mice expressed only the SPO1 $1 \beta$ isoform, as determined by immunoprecipitation/Western blotting of testis extracts. Levels of SPO11 $\beta$ in $\mathrm{Tg}(\operatorname{Spo} 11 \beta)^{+/-}$were reduced compared with Spo11 $11^{+/-}$littermates (Fig. 1A), suggesting that DSB levels may be reduced as well.

SPO11-oligonucleotide complexes are a quantitative by-product of meiotic DSB formation and therefore have been used to assess DSB levels (Neale et al. 2005; Lange et al. 2011). SPO11-oligonucleotide complexes, quantified in three independent experiments, were reduced to $44 \%, 45 \%$, and $70 \%$ in $\mathrm{Tg}(\operatorname{Spo} 11 \beta)^{+/-}$testes compared with $\operatorname{Spo} 11^{+/-}$controls (mean of $53 \%$ ) (Fig. 1A). 
A

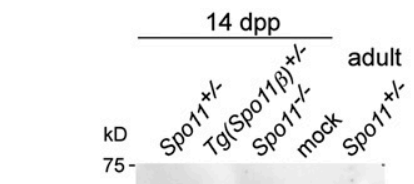

Western
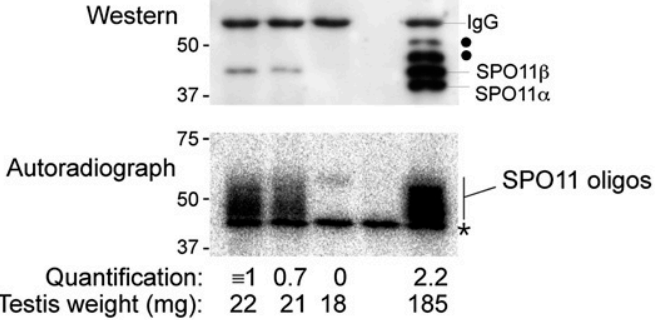

B
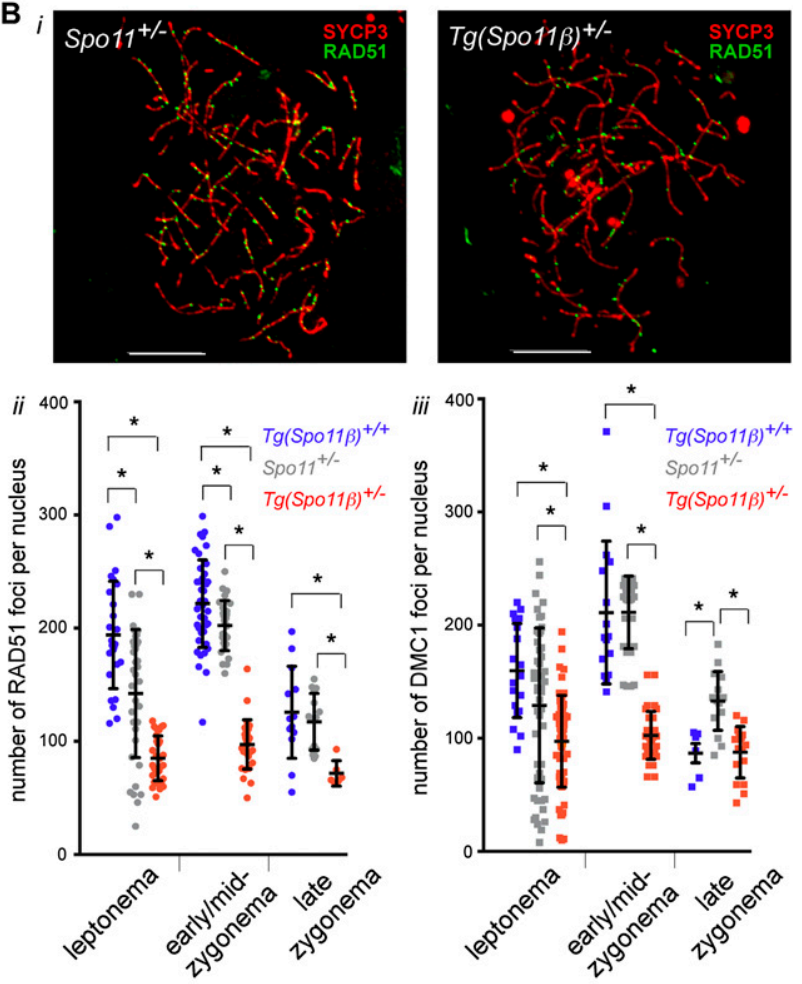

mean: 194142852222029712611772

SD: $\quad 475720 \quad 392222 \quad 412511$

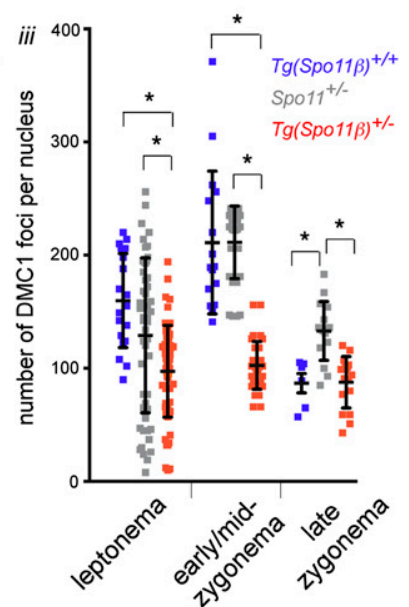

$16012997 \quad 21121196 \quad 8713388$ $426941 \quad 633221 \quad 212623$

Figure 1. Reduced DSB formation in $\mathrm{Tg}(\operatorname{Spo11} \beta)^{+/-}$males. $(A)$ Immunoprecipitation/Western blot for SPO11 (top) and labeling of SPO11-oligonucleotide complexes (bottom) from testes of juvenile and adult mice. Three independent experiments were performed; one is shown here. Filled circles mark lower-mobility bands likely originating from the Spo11 knockout allele expressed in more advanced cell types. The asterisk indicates nonspecific band. (B) Numbers of RAD51 and DMC1 foci are reduced in early prophase $\mathrm{Tg}(\mathrm{Spo} 11 \beta)^{+/-}$spermatocytes. (Panel i) Examples of IF against RAD51 and SYCP3 in early zygotene nuclei. Bars, $10 \mu \mathrm{m}$. (Panels ii,iii) Quantification of RAD51 and DMC1 foci. For each stage and all three genotypes, foci were counted in nuclei with similar SYCP3 appearance. Each dot indicates the focus count from one nucleus. Error bars indicate mean \pm SD. RAD51 focus numbers in $\mathrm{Tg}(\operatorname{Spo} 11 \beta)^{+/+}$spermatocytes were published previously (Kauppi et al. 2011, 2012). $\left(^{\star}\right) P \leq 0.0178$, two-tailed Mann-Whitney test.

RAD51 and DMC1 foci, cytological markers of DSBs, were also quantified in progressive meiotic stages. Stages were identified based on the development of chromosome axes and the SC. RAD51 and DMC1 foci are first observed at leptonema, when short stretches of axes appear marked by the SYCP3 protein. Foci peaked in number in early/mid-zygonema, when axes elongate and SC formation ensues (mean of $\sim 200$ in Spo11 ${ }^{+/-}$spermatocytes), and then dropped substantially by late zygonema, when SC is extensive (Fig. 1B). Based on detection of RAD51 and DMC1 foci in leptonema, the onset of DSB formation appeared to be normal in $\mathrm{Tg}(\text { Spo11 } \beta)^{+/-}$spermatocytes. However, focus numbers were reduced by approximately half compared with $\mathrm{Tg}(\operatorname{Spo} 11 \beta)^{+/+}$and Spo11 ${ }^{+/-}$, such that only $\sim 100$ foci on average were observed by early/mid-zygonema. By late zygonema, $\mathrm{Tg}(\operatorname{Spo} 11 \beta)^{+/-}$spermatocytes also displayed fewer RAD51/DMC1 foci, although the proportional drop in focus numbers was not as great as in Spo11 $1^{+/-}$spermatocytes.

Thus, two independent methods-quantification of SPO11-oligonucleotide complexes and RAD51/DMC1 foci-indicated an approximately twofold DSB reduction in $\mathrm{Tg}(\operatorname{Spo} 11 \beta)^{+/-}$spermatocytes. Neither method can provide a precise measure of either absolute or relative DSB numbers (SPO11-oligonucleotide complexes provide a relative, population-based measure; foci are a single-cell proxy with unknown numerical relationship to absolute DSB numbers [Kauppi et al. 2011], and both methods are influenced by DSB kinetics), but both nevertheless gave a similar estimate of lowered DSB levels. $\operatorname{Tg}(\operatorname{Spo11} \beta)^{+/-}$males therefore provide a system in which to assess the consequences of limiting DSB numbers for chromosome dynamics during mammalian meiosis.

\section{Lower DSB levels lead to a delay in SC initiation and to aberrant synapsis}

To determine whether the lower DSB levels in $\mathrm{Tg}(\operatorname{Spo} 11 \beta)^{+/-}$spermatocytes can support timely SC initiation, we examined the appearance of SYCE2, a component of the SC central element (Bolcun-Filas et al. 2007), in nuclei that displayed a level of chromosome axis formation typical of late leptonema/early zygonema. In wild-type spermatocytes, the initiation of chromosome synapsis (detected as short SYCE2 stretches) takes place early in prophase I, contemporaneously with the elongation of chromosome axes (Fig. 2A). However, in $\mathrm{Tg}(\operatorname{Spo11\beta })^{+/-}$ males, early prophase I nuclei showed markedly fewer SYCE2 stretches compared with control (Fig. 2A,B). Nuclei devoid of SC initiation were not altogether devoid of RAD51 foci, however; instead, they displayed RAD51 focus numbers characteristic of early cells for this genotype $(69 \pm 26$, mean $\pm \mathrm{SD})$. The SC initiation defect is therefore greater than the apparent DSB defect, and lower DSB levels are associated with delayed and/or reduced SC initiation.

As $\operatorname{Tg}(\operatorname{Spo11} \beta)^{+/-}$spermatocytes progressed past leptonema, we observed cell types with aberrant synaptic 

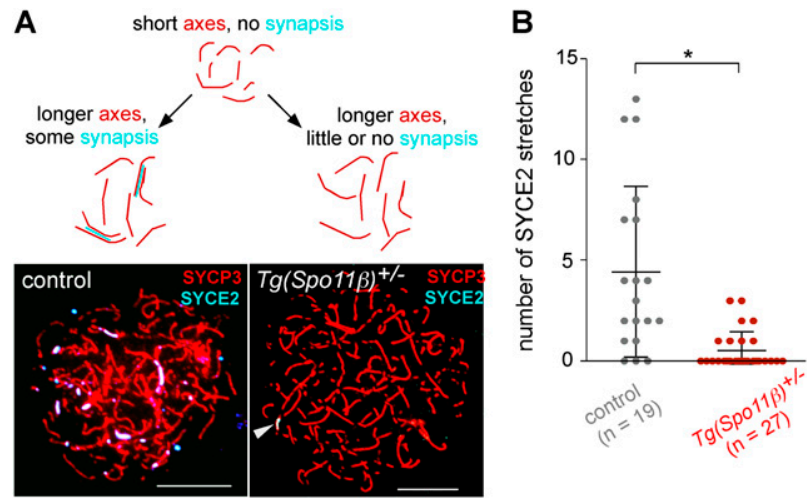

Figure 2. Delayed SC initiation in $\mathrm{Tg}(\operatorname{Spo} 11 \beta)^{+/-}$males. $(A)$ Progression of chromosome axis formation (marked by SYCP3) and the initiation of synapsis (marked by SYCE2) in normal meiosis are illustrated in the left panel of the cartoon and the IF image below. $\mathrm{Tg}(\mathrm{Spo} 11 \beta)^{+/-}$males show delayed or defective synapsis initiation, as cartooned on the right and demonstrated by the representative IF image below. Bars, $10 \mu \mathrm{m}$. The arrowhead indicates the sole SYCE2 stretch present in this nucleus. (B) Quantification of short SYCE2 stretches in nuclei judged by SYCP3 staining to correspond to late leptonema or early zygonema. Error bars indicate mean $\pm \mathrm{SD} .\left(^{\star}\right) P<0.0001$, two-tailed Mann-Whitney test.

features as well as normal-looking cell types where axis elongation was accompanied by apparently wild-type levels of SC formation (Fig. 3A,B). In contrast, autosomal synapsis is normal in males homozygous for $\mathrm{Tg}(\operatorname{Spo11\beta })$ (Kauppi et al. 2011): No autosome synaptic anomalies were observed in 193 zygotene and pachytene spermatocytes analyzed from $\mathrm{Tg}(\operatorname{Spo} 11 \beta)^{+/+}$mice. Hence, it seems likely that $\operatorname{Tg}(\operatorname{Spo11} \beta)^{+/-}$synaptic defects are tied to reduced SPO11 $\beta$ levels and, presumably, DSB numbers instead of some other feature of the transgene construct or to Spo11 $\beta$-only status.

Aberrant nuclei (which appeared to display a phenotypic continuum) were divided into two classes based on the extent of SC formation (detected by staining for SYCE2 or the SC transverse filament protein SYCP1) and the presence or absence of nonhomologous SC. Class I (zygotene-like) was defined as nuclei with aberrantly long axes but without obvious signs of nonhomologous synapsis. These nuclei displayed either little or no overall synapsis (Fig. 3A, panel i) or synapsis only between axes of similar length, thereby interpreted as likely to be homologous synapsis (Fig. 3A, panel ii). Class I nuclei are in contrast to normal zygonema, where SYCP3-stained axes develop (elongate) at the same time that homologous synapsis ensues. Since mature, elongated axes that remain unsynapsed are rarely or never observed in wild type, they can be viewed as pathological; i.e., reporting on a defect in synaptic progression.

Class II (pachytene-like) was defined as nuclei that, in addition to several normally synapsed autosomes, contained chromosome "tangles" consisting of a combination of nonhomologous synapsis, asynapsis, and homologous synapsis (Fig. 3A, panel iii). Some $T g(S p o 11 \beta)^{+/-}$ spermatocytes also displayed fully normal autosome synapsis at pachynema (Fig. 3A, panel iv). Similar to $\operatorname{Tg}(\operatorname{Spo} 11 \beta)^{+/+}$mice, $\operatorname{Tg}(\operatorname{Spo11} \beta)^{+/-}$males had a high frequency of $\mathrm{X}-\mathrm{Y}$ asynapsis in otherwise normal-looking pachytene nuclei $(50 \%, n=30$, as assessed by immunofluorescence [IF] with antibodies against SYCP3 and SYCP1) (Fig. 3A, panel iv, inset). This defect is likely due to the absence of SPO11 $\alpha$ (Kauppi et al. 2011).

The percentages of normal-appearing and aberrant spermatocyte types were quantified in adult mice (Fig. 3B). In control mice, the vast majority of cells were in pachynema and diplonema, and no aberrant cell types were observed. This contrasts with $\mathrm{Tg}(\operatorname{Spo11\beta })^{+/-}$spermatocytes, among which class II cells were the single most common cell type $(37 \%)$, while normal cell types beyond zygonema were uncommon (total $21 \%$ ).

Autosomal synaptic defects and/or unrepaired DSBs are known to result in apoptosis of spermatocytes during pachynema, while crossover failure leads to apoptosis during metaphase I (e.g., see Eaker et al. 2002; Hunt and Hassold 2002; Ahmed and de Rooij 2009). We therefore reasoned that class II nuclei and pachytene nuclei with asynaptic $\mathrm{X}$ and $\mathrm{Y}$ chromosomes may represent distinct pathological end points that would trigger apoptosis at these two different developmental stages. To test this hypothesis, TUNEL staining (indicative of apoptosis) was performed on testis sections. Each seminiferous tubule cross-section can be assigned to one of 12 epithelial stages (numbered I-XII) based on the array of germ cell developmental stages it contains (Russell et al. 1990). This staging can be used to establish the timing of apoptosis in mutants that display aberrant meiotic progression (Ahmed and de Rooij 2009).

In $\mathrm{Tg}(\operatorname{Spo1} \beta)^{+/-}$mice, TUNEL-positive primary spermatocytes were observed near the lumens of both stage IV and stage XII tubules (Fig. 3C). In contrast, Spo11-null spermatocytes undergo apoptosis exclusively in stage IV tubules (pachynema), while Mlh1-null mice, $\mathrm{Tg}(\operatorname{Spo11} \beta)$ homozygotes, and other mutants that complete autosome synapsis but have achiasmate (nonexchange) homolog pairs undergo apoptosis exclusively in stage XII tubules (metaphase I) (Baudat et al. 2000; Eaker et al. 2002; Barchi et al. 2005; Kauppi et al. 2011). Thus, the mix of stage IV and stage XII apoptosis that we observed in $\mathrm{Tg}(\text { Spo11 } \beta)^{+/-}$males is consistent with apoptosis of some cells at pachynema caused by synaptic failure and apoptosis of other cells at metaphase I caused by X-Y recombination failure. The underrepresentation of diplotene nuclei in $\mathrm{Tg}(\operatorname{Spo11} \beta)^{+/-}$males (Fig. 3B) further supports the conclusion that many cells are eliminated by apoptosis prior to this stage. Because many pachytenelike cells are eliminated, quantification of class II nuclei in adults (Fig. 3B) is likely to be an underestimate. As a result of apoptosis, $\mathrm{Tg}(\operatorname{Spo} 11 \beta)^{+/-}$testes had an abnormal cellular composition compared with control animals, such that most seminiferous tubules were smaller in diameter and contained fewer cell layers with no mature sperm in the lumen (Fig. 3C). Consequently, $\mathrm{Tg}(\operatorname{Spo11\beta })^{+/-}$ testis weights were $\sim 25 \%$ of wild type, and males were infertile (data not shown). 


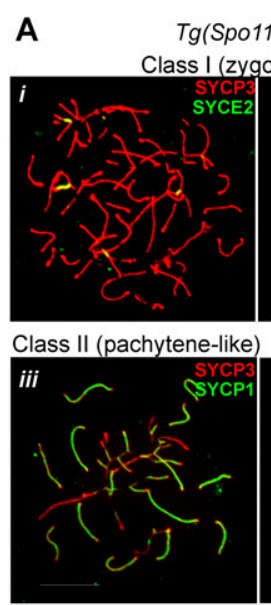

$\operatorname{TS}(\mathrm{Spo11 \beta})^{+/-}$
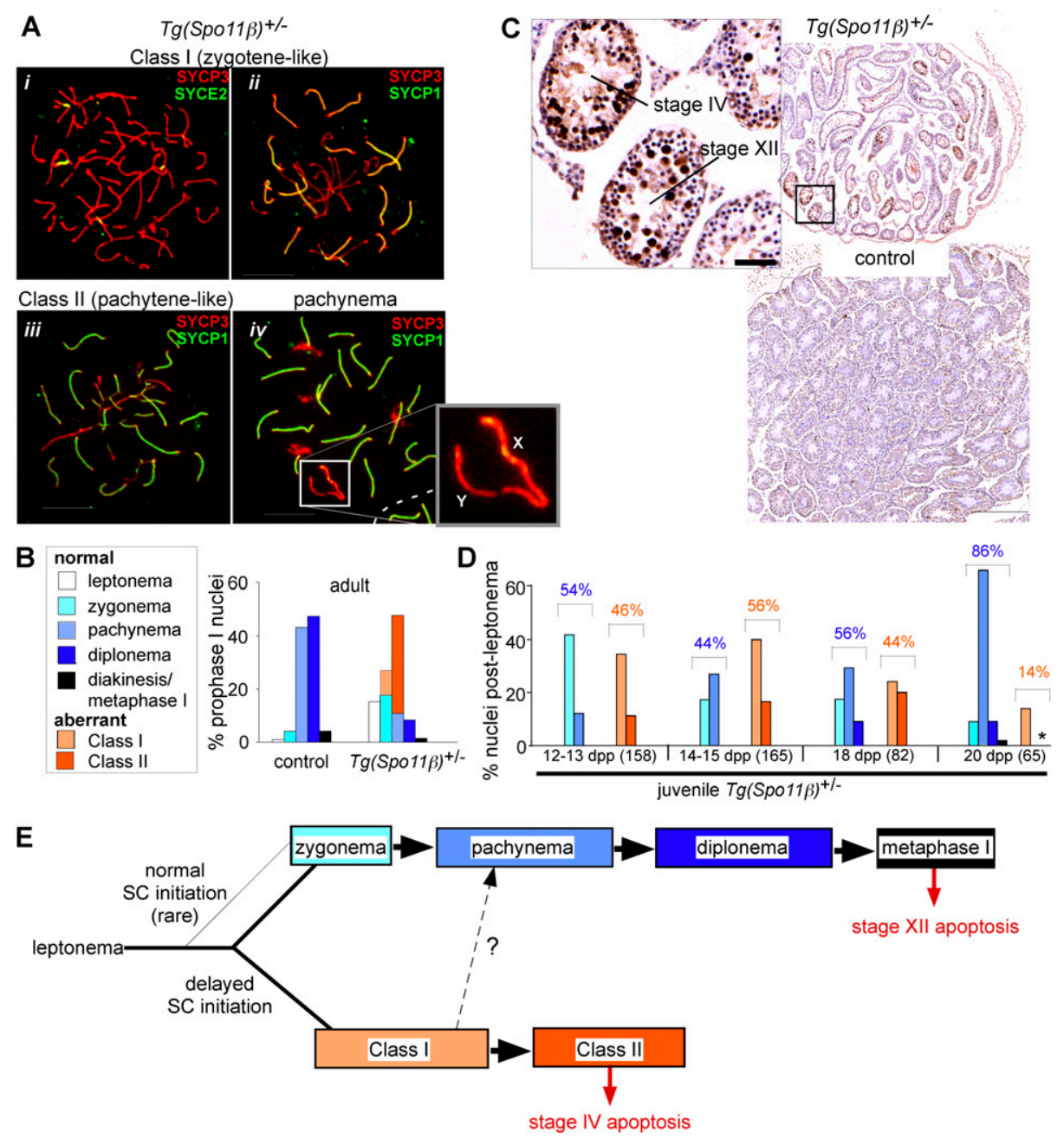

Figure 3. $\mathrm{Tg}(\operatorname{Spo} 11 \beta)^{+/-}$testes contain both aberrant and normal-looking spermatocytes. $(A)$ IF examples of cell types in $T g(\operatorname{Spo} 11 \beta)^{+/-}$ males. Aberrant classes I and II are as defined in the text. Bar, $10 \mu \mathrm{m}$. (B) Quantification of prophase I cell types in adult control and $\mathrm{Tg}(\operatorname{Spo} 11 \beta)^{+/-}$males. Approximately 200 nuclei were scored per genotype (two mice per genotype). (C) TUNEL-stained whole-testis sections of 7-wk-old mice. (Inset) Magnification of the area inside the box. Bar, $50 \mu \mathrm{m}$. (D) Timing of aberrant versus normal-appearing $\mathrm{Tg}(\mathrm{Spo11 \beta})^{+/-}$spermatocytes in juvenile mice at the indicated ages. The number of nuclei scored is shown in parentheses. The asterisk indicates the absence of class II nuclei at $20 \mathrm{dpp}$. (E) Schematic summarizing the timeline of synaptic progression in normal and aberrant $\mathrm{Tg}(\operatorname{Spo} 11 \beta)^{+/-}$spermatocytes, as inferred from analyses of juvenile and adult mice. Some class I cells may achieve normal autosomal synapsis; i.e., progress to normal pachynema (dashed arrow).

\section{Timing of homologous versus nonhomologous synapsis}

To investigate temporal patterns of chromosome tangle formation, we quantified cell types in juvenile $\mathrm{Tg}(\mathrm{Spo} 11 \beta)^{+/-}$ animals during the first wave of spermatogenesis, where meiosis progresses semisynchronously. Since a subset of $\mathrm{Tg}(\mathrm{Spo11 \beta})^{+/-}$spermatocytes display normal-appearing autosomal synapsis, the dynamics of normal and aberrant cell types could be compared within the same mice (Fig. 3D). At 12-13 dpp, both normal-looking zygotene cells and class I (zygotene-like) cells were seen at similar frequencies, indicating that normal and aberrant cell types appear contemporaneously. At $14-15 \mathrm{dpp}$, the most common normal-appearing cell type was pachynema; in contrast, most aberrant cells were still class I (that is, with long axes but modest SC formation). At $18 \mathrm{dpp}$, the abundance of class II cells almost reached that of class I cells.

Thus, the rise in abundance of class II cells is delayed compared with that of normal-looking pachytene cells, which suggests that nonhomologous synapsis occurs relatively late. Note that class II cells were not as abundant in juvenile mice as in adults (see Fig. 3B); this may be due to an increasing propensity for nonhomologous synapsis with age (Vasco et al. 2012). Of the ages examined, the contrast between the relative abundance of normal versus aberrant cell types was most pronounced at $20 \mathrm{dpp}$. Abundant normal pachytene cells were seen as well as some more advanced normal-looking cell types but no class II cells (Fig. 3D, asterisk). The absence of class II cells at this age is likely due to their 
efficient elimination by apoptosis. Consistent with this, many epithelial stage IV tubules in 20 dpp testis sections contained TUNEL-positive spermatocytes (Supplemental Fig. 1A,B), implying cell death at a pachytene-like stage. Wild-type meiotic progression does not result in an appreciable number of TUNEL-positive primary spermatocytes at these ages (e.g., see Dix et al. 1997; Baudat et al. 2000). A summary of the progression of normal and aberrant synapsis in $\mathrm{Tg}(\operatorname{Spo11} \beta)^{+/-}$spermatocytes, as inferred from these data, is provided in Figure 3E.

\section{Not all chromosomes are equally prone to tangling}

Within class II nuclei, there was substantial cell-to-cell variation in the extent of synaptic defects, ranging from just a few nonhomologously synapsed chromosomes to the majority of autosomes being tangled (Fig. 4A). This observation, along with the fact that a subset of cells achieved full autosomal synapsis, demonstrates that synaptic defects are partially penetrant and suggests a stochastic component to the reduction in DSB number and/ or to the effect that DSB reduction has on homolog synapsis.
Because class II nuclei contain chromosomes involved in both homologous and nonhomologous synapsis, it was possible to ask whether some chromosomes are more prone than others to aberrant synapsis; that is, more sensitive to DSB reduction. Conceivably, larger chromosomes could be more likely to get entangled simply because longer axes may be more affected by topological constraints on synapsis and by interlocking (chromosome axes trapped within SCs of other chromosomes). Alternatively, if size (axis length) is what determines how many DSBs a chromosome receives, smaller chromosomes could be more vulnerable when faced with DSB reduction. To distinguish between these possibilities, we performed immuno-fluorescence in situ hybridization (immuno-FISH) for the two largest (chromosomes 1 and 2) and two smallest (chromosomes 18 and 19) autosomes as well as the $\mathrm{X}$ and $\mathrm{Y}$ (see examples in Fig. $4 B, C)$. The frequency of participation in tangles was relatively low for any one autosome tested (Supplemental Fig. 2); this implies high cell-to-cell variability, consistent with a stochastic component that likely underlies the partially penetrant synaptic defects. Small autosomes participated in tangles more frequently than large ones
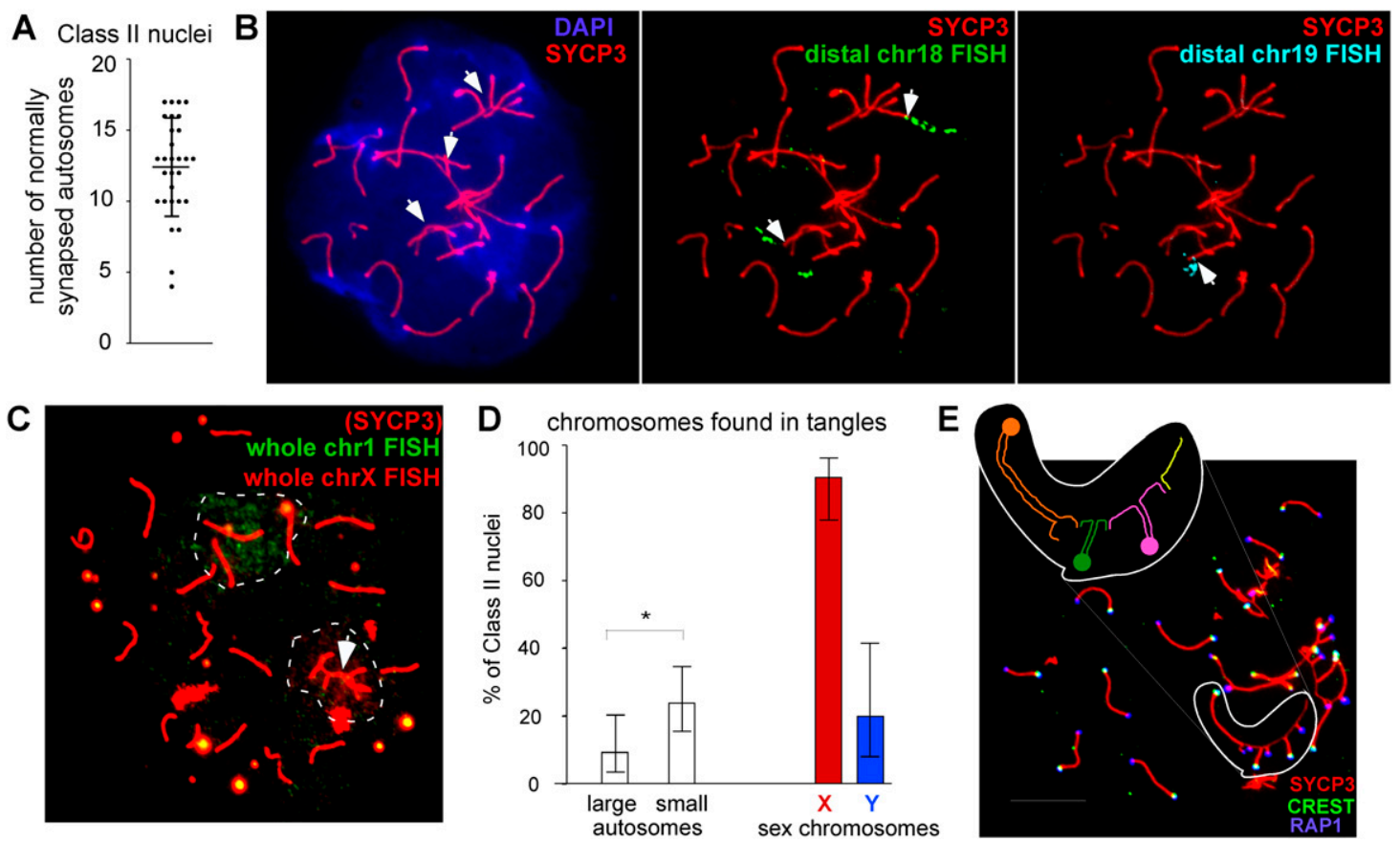

Figure 4. Chromosome configurations in class II nuclei. (A) Quantification of the number of normally synapsed autosomes in class II nuclei. Error bars indicate mean (12.4) \pm SD. $(B, C)$ Examples of immuno-FISH on class II spermatocytes to reveal the identity of chromosomes involved in nonhomologous synapsis. (B, left) IF against SYCP3, with arrows indicating chromosome tangles. The middle and right images show FISH using bacterial artificial chromosome (BAC)-based probes against centromere-distal regions of chromosomes 18 and 19, respectively. In this example, the two chromosomes 18 are in separate tangles, synapsed with nonhomologous partners, while chromosome 19 appears correctly synapsed. (C) Immuno-FISH with whole-chromosome probes against chromosome 1 and the X chromosome. The dashed lines highlight FISH signals. In this example, chromosome 1 is correctly synapsed, while the $\mathrm{X}$ chromosome is in the tangle (arrow). (D) Quantification of the involvement of large (chromosomes 1 and 2) and small (chromosomes 18 and 19) autosomes and sex chromosomes in nonhomologous synaptic configurations. Error bars show upper and lower $95 \%$ confidence intervals. Only class II nuclei with at least five properly synapsed autosomes were considered. $\left(^{*}\right) P=0.037$, Fisher's exact test $($ twotailed). (E) Example of a class II spermatocyte nucleus with daisy chain tangles. Cartoon shows inferred configuration of homologously and nonhomologously synapsed regions, with different homologs shown in different colors. 
(Fig. 4D; Supplemental Fig. 2). The X chromosome was involved in tangles in nearly all class II nuclei (Fig. 4C,D). Therefore, some chromosomes are more prone than others to illegitimate synapsis under reduced DSB conditions (X chromosome $\gg$ small autosomes $>$ large autosomes). Compared with the $\mathrm{X}$ chromosome, the $\mathrm{Y}$ chromosome seems to be relatively resistant to tangling.

\section{Chromosome configurations within tangles}

In some favorably spread class II nuclei, chromosome axes adopted a daisy chain-like configuration with apparently alternating homologous and nonhomologous synapsis (Fig. 4E). In these nuclei, it was possible to trace tangled chromosome axes and their synaptic partner switches and thus obtain a more detailed view of chromosome tangles. Because mouse chromosomes are acrocentric, IF with an antibody against a centromere marker (e.g., CREST antiserum) can distinguish between the centromeric and noncentromeric ends. To establish the orientation of tangled chromosome axes, we used IF to visualize CREST antibodies and the telomere marker RAP1. Combining this information with the length of chromosome axes involved in tangles allowed homologously versus nonhomologously synapsed regions to be inferred (cartooned in Fig. 4E, inset). Centromere-distal subtelomeric regions were often involved in nonhomologous synapsis (Fig. 4E; data not shown). If behavior of these cytologically favorable cells is representative, it may indicate that aberrant synapsis of subtelomeric regions is facilitated by the spatial proximity in the nucleus due to chromosomes in early meiosis being attached to the nuclear envelope by their telomeres (Scherthan et al. 1996). Centromere-proximal subtelomeric regions, on the other hand, may be shielded from nonhomologous synapsis if centromeric regions impede SC polymerization as proposed (Henderson and Keeney 2005; Qiao et al. 2012).

\section{Continued DSB formation on unsynapsed chromosome axes}

If aberrant synapsis is provoked by chromosomes that do not have enough DSBs to support homolog pairing, one might expect to see few DSB markers on those chromosomes that display pairing/synapsis defects. Surprisingly, however, class II nuclei often displayed abundant RAD51 foci on unsynapsed axes in chromosome tangles (Fig. 5A, panel ii). We hypothesized that these foci may mark DSBs that form later, specifically on unsynapsed axes. To examine this question, the density of RAD51 foci was measured on unsynapsed axes in nuclei with varying extents of total synapsis (Fig. 5A,B). In control animals, RAD51 focus density on unsynapsed chromosome axes remained relatively constant irrespective of the extent of nucleus-wide synapsis. This is consistent with most DSBs in wild-type cells forming early and at a high enough density to allow for progressive pairing and recombination to work efficiently.

Spermatocytes from $\mathrm{Tg}(\operatorname{Spo} 11 \beta)^{+/-}$males with little to intermediate $(0 \%-70 \%)$ synapsis showed a twofold to threefold lower RAD51 density compared with controls (Fig. 5B), in accordance with the lower total DSB numbers characteristic of this genotype (Fig. 1). However, nuclei with more extensive overall synapsis $(>70 \%)$ had a substantially higher density of RAD51 foci on unsynapsed axes (Fig. 5B). The temporal analysis of cell types above (Fig. 3D) indicated that spermatocytes with more extensive synapsis are cells that have progressed further in meiosis. Thus, only in later cells does the RAD51 focus density approach that seen in controls. The nuclei with higher synapsis percentage cannot be ascribed to a hypothetical subset of cells that formed a high number of DSBs in the first place because $\mathrm{Tg}(\operatorname{Spo} 11 \beta)^{++-}$males displayed virtually no early prophase cells with a normal total RAD51 number (i.e., early/ mid-zygotene cells in Figure 1B, panel ii) or RAD51 density on unsynapsed axes (i.e., cells with $<10 \%$ synapsis in Fig. $5 B)$. We interpret the higher RAD51 focus density to mean that unsynapsed axes receive additional DSBs later and that these DSBs persist because the axes trapped in chromosome tangles are topologically constrained and therefore are unable to complete interhomolog repair.

Based on these results in the pathological situation in $\mathrm{Tg}(\operatorname{Spo11} \beta)^{+/-}$cells, we hypothesized that unsynapsed chromosome axes in fully wild-type mice might also be subjected to continued DSB formation. To test this, we examined RAD51 foci on the X chromosome in males. Unlike autosomes, the $\mathrm{X}$ has no homologous pairing partner, except for the pseudoautosomal region (PAR), a short $(<1-\mathrm{Mb})$ region of homology shared between the $\mathrm{X}$ and $\mathrm{Y}$ (Perry et al. 2001). The much larger non-PAR portion of the $\mathrm{X}(166 \mathrm{Mb})$ remains obligately asynaptic. (The other obligately asynaptic chromosome segment, the non-PAR portion of the $\mathrm{Y}$, is not amenable to similar analysis because it displays no or very few RAD51 foci [Kauppi et al. 2011]). The PAR of the X chromosome was identified using immuno-FISH, and RAD51 foci were counted on the non-PAR portion of the $\mathrm{X}$ chromosome axis in early/mid- and late zygotene cells (Fig. 5C-E). We considered RAD51 foci on the 3.5- $\mu \mathrm{m}$ stretch immediately adjacent to the FISH probe (a length that was informative in both early/mid- and late zygotene nuclei) or the entire length of axis marked by SYCP3 (variable from cell to cell and, on average, shorter in earlier nuclei). Both analyses revealed an approximately twofold increase in RAD51 foci in later stage nuclei compared with earlier nuclei (Fig. 5D,E), indicating continuous DSB formation on this asynaptic chromosome segment. It is unlikely that the observed increase in focus density is caused by a change in megabase/micrometer DNA content of unsynapsed axis, since the axis length of the PAR, located immediately adjacent, did not detectably change $0.6 \pm$ $0.1 \mu \mathrm{m}$, mean $\pm \mathrm{SD}$, in both early/mid- and late-zygotene cells; $n \geq 12$ ). These results imply that the mechanism responsible for increased RAD51 focus density on unsynapsed chromosome axes operates not only in late $\mathrm{Tg}(\operatorname{Spo11\beta })^{+/-}$spermatocytes, but also in wild-type cells.

\section{Discussion}

Analysis of $\mathrm{Tg}(\operatorname{Spo11} \beta)^{+/-}$mice uncovered two previously unappreciated aspects of meiotic chromosome dynamics: 
A

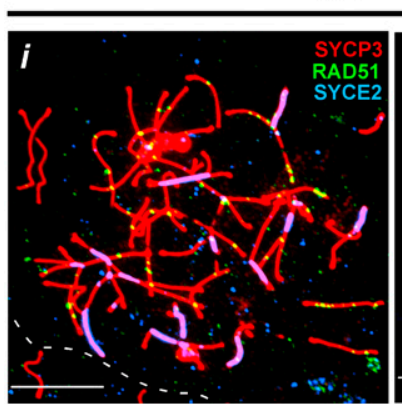

$\operatorname{Tg}(\mathrm{Spo11 \beta})^{+/-}$

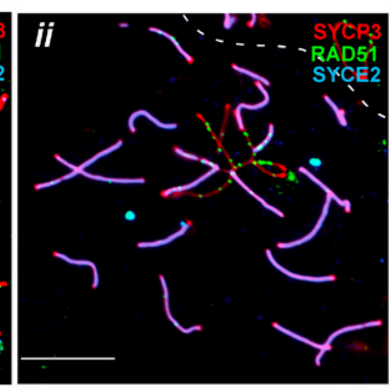

C

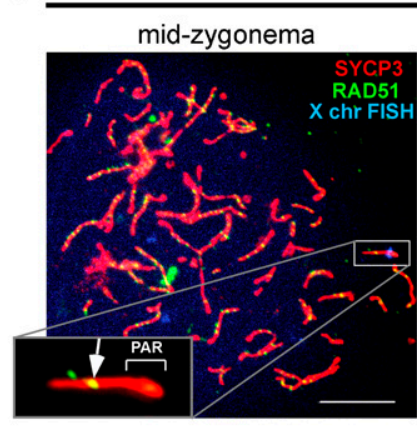

wild-type

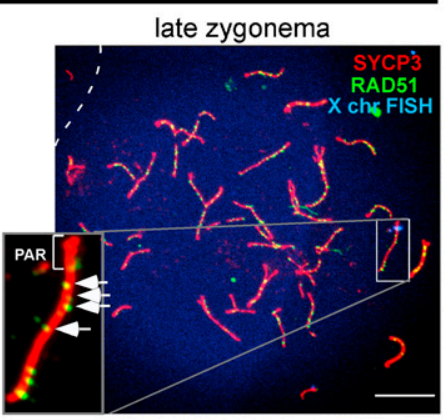

B
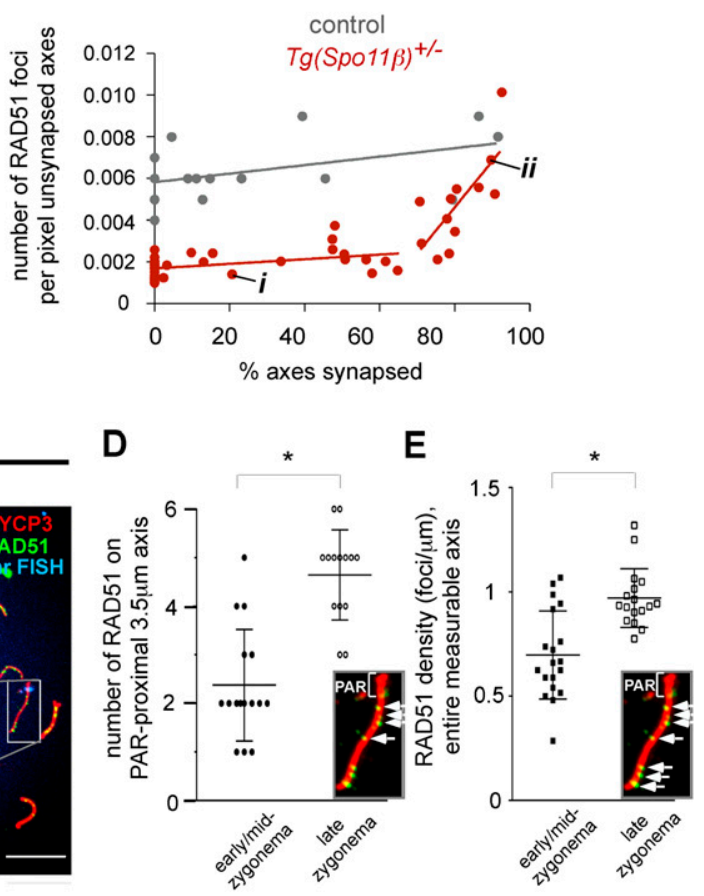

Figure 5. Synapsis and RAD51 focus density. (A) IF examples of nuclei with modest (panel i) or extensive (panel ii) synapsis, presumably earlier and later in prophase, respectively. Dashed lines indicate boundaries with other spermatocyte nuclei nearby. Bars, $10 \mu \mathrm{m} .(B)$ RAD51 density on unsynapsed axes increases in late nuclei of $\mathrm{Tg}(\operatorname{Spo} 11 \beta)^{+/-}$mice. The genotype for controls was $S p o 11^{+/-}$ $\mathrm{Tg}(\operatorname{Spo11} \beta)^{+/-}$. Each dot shows the RAD51 focus density from one nucleus, ordered according to the extent of synapsis nucleus-wide. The points for the nuclei shown in panels $i$ and ii in $A$ are indicated. With the exception of nuclei showing $0 \%$ synapsis, all nuclei analyzed for $\mathrm{Tg}(\mathrm{Spo} 11 \beta)^{+/-}$were aberrant cell types. (Lines) Linear regression. The two red lines are for nuclei with $<70 \%$ synapsis and $>70 \%$ synapsis, to highlight the apparently biphasic RAD51 focus density in $T g(\operatorname{Spo} 11 \beta)^{+/-}$. $(C)$ Examples of RAD51 foci on the X chromosome in wild-type spermatocytes. Images show overlays of IF for RAD51 and SYCP3 and FISH with an X chromosome BAC probe hybridizing to the PAR boundary. Bar, $10 \mu \mathrm{m}$. The insets show magnifications of the $\mathrm{X}$ chromosome axis, with arrows pointing to examples of RAD51 foci. $(D)$ RAD51 foci on the $3.5 \mu \mathrm{m}$ of X chromosome axis closest to the PAR (see example from $C$ in the inset; counted foci are indicated by white arrows). Each dot shows the RAD51 focus count from a nucleus of the indicated stage. Error bars indicate mean $\pm \mathrm{SD} .\left(^{\star}\right) P<0.0001$, two-tailed Mann-Whitney test. $(E)$ Density of RAD51 foci along the entire measurable length of the PARproximal $\mathrm{X}$ chromosome axis (see example from $C$ in the inset; counted foci are indicated by white arrows). Each dot shows the RAD51 focus density from a nucleus of the indicated stage. Error bars indicate mean $\pm \mathrm{SD} .\left(^{\star}\right) P=0.0008$, two-tailed Mann-Whitney test.

the differential vulnerability of particular chromosomes to DSB reduction and continued DSB formation on chromosome axes that fail to synapse. The former finding suggests that one important function of the seemingly excessive number of DSBs (>200) in wild-type meiosis is to ensure that even the smallest chromosomes receive enough DSBs to find and synapse with their homologs. In other words, the DSB set point in wild-type cells is largely driven by the pairing requirements of the most vulnerable chromosomes. One outstanding question is where the threshold lies for "just enough" DSBs for mammalian meiosis. Our data cannot provide a direct answer because of intrinsic uncertainty in DSB measurements and the lack of genetic tools to further titrate DSB numbers (Supplemental Table 1). Nevertheless, we show here that having approximately half the normal DSB level is usually not enough.

A simple explanation for the vulnerability of small chromosomes to reduced DSB levels is that nucleus-wide
DSBs are distributed among autosomes proportionately to axis length. Large chromosomes, then, would receive more DSBs in absolute terms than small ones and thereby enjoy a "DSB buffer" even when the total nucleus-wide DSB number is low (Supplemental Fig. 3). These data agree well with those from fungi. However, because of the suitability of mouse chromosome preparations for detailed cytological analyses, our findings provide unprecedented insight into interchromosomal differences in DSB requirements for pairing.

Unlike fungi, mammalian spermatocytes have the challenging task of pairing their heteromorphic sex chromosomes. We found that under conditions of reduced DSBs, the $\mathrm{X}$ chromosome is especially prone to illegitimate synapsis. This may be because it has a long chromosome axis that lacks a homologous partner. In $\operatorname{Tg}(\operatorname{Spo11\beta })^{+/-}$ spermatocytes, where autosomal synapsis is often perturbed, the obligately asynaptic $\mathrm{X}$ chromosome axis may engage in nonhomologous synapsis with autosomes that 
failed to synapse with their homolog in a timely manner. The male-specific (non-PAR) region of the $\mathrm{Y}$ chromosome, on the other hand, seems to be relatively resistant to this kind of misbehavior (although it can form substantial nonhomologous SC with the $\mathrm{X}$ in some strain backgrounds) (Tres 1977; Page et al. 2012). The propensity of the $\mathrm{X}$ chromosome to engage in and promote nonhomologous synapsis adds a new entry to the list of potential misbehaviors of sex chromosomes in males, which previously included susceptibility to $\mathrm{X}-\mathrm{Y}$ recombination failure (Shi et al. 2001; Kauppi et al. 2011) and gross chromosomal rearrangements of the $\mathrm{X}$ and $\mathrm{Y}$ triggered by DSBs in segments lacking an allelic homologous partner (Lange et al. 2009; Sasaki et al. 2010).

It was demonstrated previously that modulating SPO11 protein levels affects DSB numbers in a nonlinear fashion (Lange et al. 2011; Cole et al. 2012). In fact, given that free SPO11-at least as assayed in a cell population-appears to be in excess (Neale et al. 2005; Lange et al. 2011), one would not necessarily predict that a relatively modest reduction in SPO11 levels should have any effect on DSB numbers. $\mathrm{Tg}(\operatorname{Spo} 11 \beta)^{+/-}$spermatocytes, however, display substantially reduced DSB levels. The lack of a strict linear relationship between SPO11 protein levels and DSB levels could be due to, for example, DSB feedback mechanisms (Lange et al. 2011; this study) and/or stoichiometry of SPO11 isoforms or DSB proteins generally. $\mathrm{Tg}(\operatorname{Spo} 11 \beta)^{+/-}$males, because they do not possess a full suite of Spo11 splice isoforms, may be more sensitive to altered SPO11 dosage than Spo11 $1^{+/-}$mice.

Two key differences in SPO11 protein expression in $\mathrm{Tg}(\operatorname{Spo} 11 \beta)^{+/-}$males compared with wild type are that SPO $11 \alpha$ is absent and total SPO11 levels are reduced. Synaptic defects cannot be ascribed to the absence of SPO $11 \alpha$ per se because autosomal synapsis in $\mathrm{Tg}(\operatorname{Spo} 11 \beta)^{+/+}$ mice of both sexes and in $\mathrm{Tg}(\operatorname{Spo} 11 \beta)^{+/-}$females is normal (Supplemental Fig. 4; Kauppi et al. 2011). Instead, we infer that the defects in $\mathrm{Tg}(\operatorname{Spo} 11 \beta)^{+/-}$males are directly tied to reduced SPO $11 \beta$ levels. Since DSB formation is the most clearly established function of SPO11 in all organisms where it has been tested, we favor the simple interpretation that early-forming DSBs in $\mathrm{Tg}(\operatorname{Spo11} \beta)^{+/-}$males are reduced to a level that can no longer support efficient homolog synapsis. However, a DSB-independent role for Spol1 in early meiotic homolog pairing has been suggested in budding yeast and mice (Cha et al. 2000; Boateng et al. 2013). Although we cannot exclude the formal possibility that reduced SPO11 $\beta$ levels cause synaptic defects by compromising a putative noncatalytic function of SPO11 instead of or in addition to reducing DSB numbers, it is not clear how a structural role for the protein would preferentially suppress nonhomologous synapsis of the sex chromosomes and small autosomes.

The temporal difference in the appearance of normallooking pachytene cells versus aberrant (class II) cells in $\mathrm{Tg}(\operatorname{Spo} 11 \beta)^{+/-}$juvenile mice supports a previously described two-phase model of chromosome synapsis, with SC formation between homologous regions occurring earlier than between nonhomologous regions (Moses et al. 1984; Zickler and Kleckner 1999). In this model, only homologous synapsis can take place in zygonema; nonhomologous synapsis is disfavored until pachynema, at which point more promiscuous synapsis is permitted (Moses et al. 1984). This model was developed largely based on cytological studies of translocations, inversions, or rearrangements (McClintock 1933; Rasmussen and Holm 1978; Moses and Poorman 1981; Moses et al. 1982; de Boer et al. 1986; Borodin et al. 1991); for a comprehensive discussion, see Moses et al. (1984); Zickler and Kleckner (1999) and references therein. We now provide evidence in support of this model in a karyotypically normal mammalian system.

In contrast to the catastrophic defects seen in mouse spermatocytes, budding yeast with a roughly twofold reduction in DSBs usually complete meiosis successfully (Martini et al. 2006). It is possible that yeast make a larger "excess" of DSBs than mice relative to the number needed to ensure chromosome pairing and segregation. However, it is also possible that this difference is more due to contrasting outcomes when there are too few DSBs. For instance, yeast chromosomes may be less prone to nonhomologous synapsis when DSB numbers are low and therefore may be less likely to become tangled. Our results suggest that lack of an obligately asynaptic heteromorphic chromosome pair in yeast is an important difference in this context. Moreover, the abundance of repeated sequences in the mouse genome might render it more prone to nonallelic interactions unless a sufficient number of DSBs help promote homologous synapsis. Unlike mouse spermatocytes, yeast cells experiencing even complete asynapsis progress efficiently through meiosis (Henderson and Keeney 2004); thus, achiasmy rather than asynapsis is probably the more important limiting factor for meiotic failure. Such interspecies differences further emphasize the importance of direct analysis of meiosis in mammals.

We demonstrate here that karyotype critically impinges on the interplay between recombination and homolog synapsis. A model consolidating our findings is shown in Figure 6. During the "first phase" of synapsis, only multiple DSB-driven homolog interactions are sufficiently stable to overcome forces that disrupt pairing interactions (e.g., telomere-led chromosome movements in zygonema likely being an important factor) (Sato et al. 2009). Decelerating chromosome movements and/or other factors may make the nucleus permissive for the stabilization of nonhomologous synapsis during the "second phase." In wild-type nuclei, this is of little consequence, since most chromosome axes have already synapsed homologously, shielding them from illegitimate synapsis. However, when a nucleus receives a lower than normal number of DSBs, the non-PAR portion of the $\mathrm{X}$ chromosome is often the instigator of illegitimate synapsis but still requires the presence of a DSB-poor autosome as a partner. Once an autosome has engaged in nonhomologous synapsis, its homolog (now the orphan chromosome) (Fig. 6) may be more likely to engage in further nonhomologous synapsis. In this view, the asynapsed portion of the $\mathrm{X}$ chromosome frequently triggers a chain reaction of autosome misbehavior. This model predicts that the female 


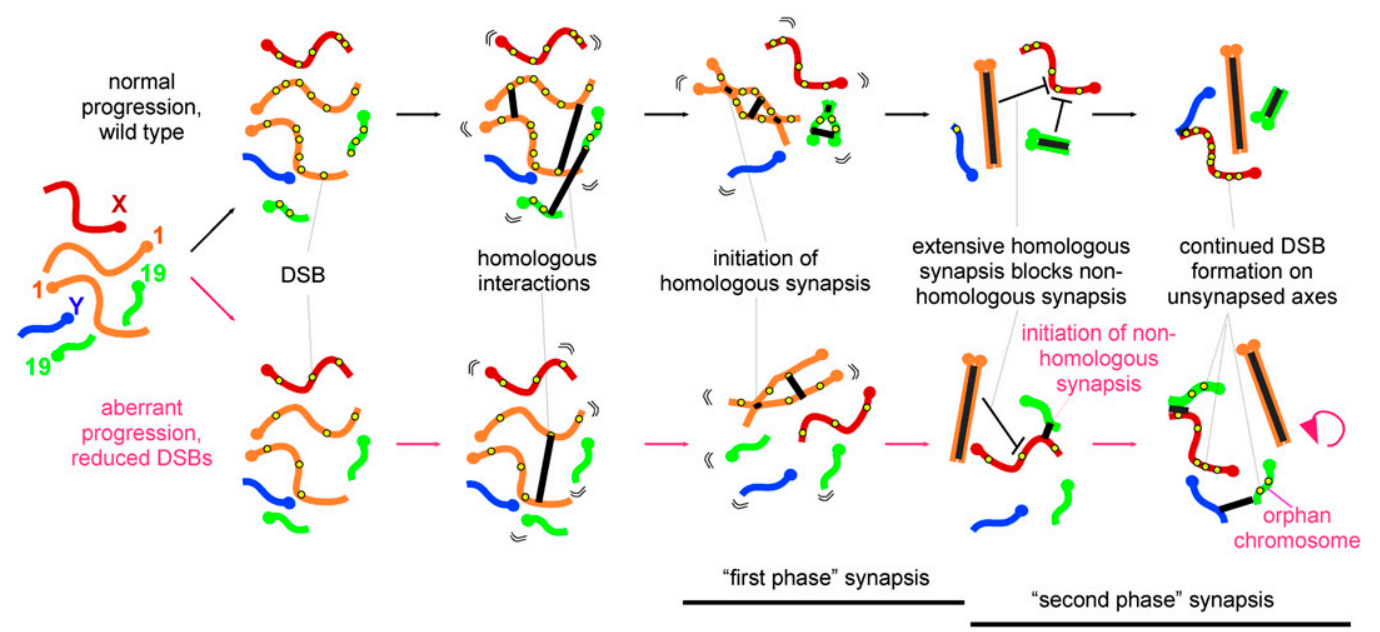

Figure 6. Model summarizing the chromosome-specific effects of DSB reduction and continued DSB formation on unsynapsed axes. SPO11-dependent DSBs are indicated as yellow circles. Pairing interactions and subsequent synapsis are shown as thick black lines. When DSB levels are reduced, "first phase" autosomal synapsis is partially impaired. During the later, "second phase" of synapsis, chromosome axes that remain unsynapsed can undergo nonhomologous synapsis. This process nearly always involves a synaptic interaction of the X chromosome with an autosome (frequently a small one) that, because of an insufficient number of DSBs, failed to synapse with its homolog during the "first phase." The remaining orphan homolog, now left without a pairing partner, may be more likely to engage in additional nonhomologous synapsis. We propose that chromosome synapsis shuts down de novo DSB formation, whereas chromosome axes that remain unsynapsed continue to undergo DSB formation.

germline, which contains two fully homologous X chromosomes, may better tolerate lower DSB numbers. Unfortunately, $\mathrm{Tg}(\operatorname{Spo} 11 \beta)^{+/-}$females do not allow us to test this prediction because, unlike males, they showed normal RAD51 focus levels, meiotic progression, and fertility (Supplemental Fig. 4).

Our data from both $\mathrm{Tg}(\operatorname{Spo} 11 \beta)^{+/-}$and wild-type spermatocytes imply that chromosome axes that remain in an unsynapsed state experience additional de novo DSBs as meiosis progresses. Appreciable numbers of RAD51 foci on unsynapsed chromosome segments have been reported in several mouse mutants but have generally been interpreted as persistent DSBs rather than continuously formed ones (Plug et al. 1998; Edelmann et al. 1999; Kneitz et al. 2000; de Vries et al. 2005). Similarly, the numerous RAD51 foci observed on the unsynapsed portion of the $\mathrm{X}$ chromosome in normal males have been taken as an indication of persistent DSBs (Moens et al. 1997; Oliver-Bonet et al. 2005), although it has been noted that down-regulation of DSB formation might accompany SC formation (Wojtasz et al. 2009). Based on RAD-51 focus dynamics in nematodes with DNA translocations, Villeneuve and coworkers (Hayashi et al. 2007; Henzel et al. 2011) argued for continuous DSB formation and further proposed that the abundant RAD-51 foci observed in rec-8 mutant worms (Alpi et al. 2003) could be due to loss of REC-8-dependent DSB suppression (Hayashi et al. 2007). However, neither mouse nor nematode experiments to date could distinguish between persistence of DSBs and formation of additional new DSBs.

We now provide the first evidence for continued DSB formation on asynapsed chromosomal regions in mammals. Asynapsis might actively promote late DSB formation, and/or asynapsed regions could remain permissive to DSB formation until some feature of homolog engagement shuts it off. Either way, this system behaves functionally as a feedback mechanism in which interhomolog interactions (or lack thereof) regulate the occurrence of the very events (i.e., DSBs) that lead to interhomolog interactions. In wild-type cells, additional DSBs on unsynapsed axes could serve to promote timely completion of autosomal synapsis. Thus, we envision that the normal function of this feedback system is to make homolog pairing and synapsis robust against stochastic cell-to-cell and chromosome-to-chromosome variation in DSB numbers. In the face of the severe DSB decrement in $\mathrm{Tg}(\mathrm{Spo11 \beta})^{+/-}$ spermatocytes, however, continued DSB formation is too little and/or too late; that is, likely to be futile for promoting fully normal homolog synapsis if extensive stretches of axes are already locked in nonhomologous synaptic configurations. An alternative, nonexclusive, possibility is that DSBs that form later serve to amplify DNA damage signaling from unsynapsed regions to help trigger apoptosis. At present, it is not clear how the DSB feedback mechanism that we propose here may relate to the one that is severed in $\mathrm{Atm}^{-/-}$mice (Lange et al. 2011) and flies (Joyce et al. 2011) or to the cis- and trans-acting mechanisms described in budding yeast (Xu and Kleckner 1995; Rocco and Nicolas 1996; Zhang et al. 2011). However, it is conceivable that there are multiple DSB feedback loops-one can envision, for instance, that a mechanism mediated by a kinase (e.g., ATM) could enforce transient, local DSB suppression, while stable homolog engagement (e.g., synapsis) could have a longer-lasting effect that acts over longer distances.

The feedback process proposed here is attractive because it involves a mechanism that, in wild-type cells, would target additional DSBs specifically to chromosomal 
regions where they are needed. How might the DSB machinery distinguish between genomic regions that have engaged their homologs and those that have not? This process may be mediated by differences in protein composition; for example, in HORMAD proteins that are evicted from chromosome axes shortly after synapsis (Woitasz et al. 2009). In this context, it is noteworthy that DSBs appear substantially reduced in the absence of HORMAD1 (Shin et al. 2010; Daniel et al. 2011), whereas DSB markers are elevated in Trip $13^{-/-}$mice where HORMAD proteins are retained on synapsed axes (Roig et al. 2010). The latter observation was interpreted to indicate delayed DSB turnover but is equally compatible with continuous de novo DSB formation on synapsed (but HORMAD-laden) axes.

We demonstrate here that some chromosomes are more sensitive to reduced DSB levels than others: Small chromosomes are the weak link of mammalian meiotic chromosomes in general and the $\mathrm{X}$ chromosome at least in the male germline. These findings have important implications for the viability of wild-type meiocytes, since there is substantial cell-to-cell variation in DSB numbers (Chen et al. 2008; Cole et al. 2012). A cell that receives a low total DSB number might be predisposed to experiencing synaptic defects like those seen in $\mathrm{Tg}(\mathrm{Spo11} \beta)^{+/-}$males. Remarkably similar synaptic defects, with nonhomologous synapsis involving subtelomeric autosomal regions and the male $\mathrm{X}$ chromosome, have been reported in humans (Bojko 1983; Holm 1978). This suggests that the challenges of chromosome synapsis uncovered here in the mouse may be generally applicable to complex mammalian genomes. Furthermore, any genetic variants in humans that reduce overall meiotic DSB levels might be expected to lead to fertility problems.

\section{Materials and methods}

Mice

Mice were obtained from the following crosses: Spo11 ${ }^{+/-}$

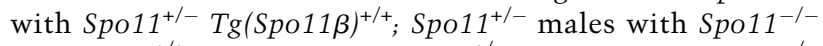

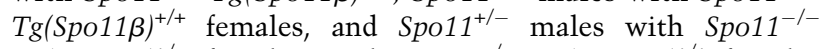
$\mathrm{Tg}(\operatorname{Spo} 11 \beta)^{+/-}$females. Both Spo11 ${ }^{-/-} \mathrm{Tg}(\operatorname{Spo} 11 \beta)^{+/+}$females and $S p o 11^{-1-} \mathrm{Tg}(S p o 11 \beta)^{+/-}$females are fertile (Kauppi et al. 2011 ; this study). The Spo11 $\beta$ transgene construct and Spo11 ${ }^{+/-}$ mice have been described previously (Baudat et al. 2000; Kauppi et al. 2011). Meiotic progression in both $S p o 11^{+/}$and $S p o 11^{+/-}$ $\mathrm{Tg}(\operatorname{Spo11\beta })^{+/-}$is normal, so both were used as controls in the experiments described in this study. For all DSB quantification experiments, where Spo11 gene dosage may have a stronger effect, Spo11 $1^{+-}$animals (without transgene) were used as the control for Spo11 ${ }^{-/-} \mathrm{Tg}(\operatorname{Spo11\beta })^{+/-}$.

$\mathrm{Tg}$ (Spo11ß) genotyping was performed by Southern blot using a gel-purified PCR fragment corresponding to part of the Spo11 cDNA as a probe or by PCR (primers Xb3T-F1 [5'-TGGTTTA GAGTTTGGCAACA-3'], Xb3G-F1 [5'-TGAAAAGAGCCTCA GGTTTC-3'], and Xb3-R1 [5'-ATCGTCCAGGATCTTTGTGT-3']; PCR product size was 219 base pairs [bp] when the transgene was absent and $369 \mathrm{bp}$ when the transgene was present). Genotyping for the endogenous Spo11 locus was performed by PCR of toe or tail tip DNA using Direct Tail lysis buffer (Viagen) following the manufacturer's instructions. Experiments conformed to relevant regulatory standards and were approved by the Memorial SloanKettering Cancer Center (MSKCC) Institutional Animal Care and Use Committee.

\section{SPO11-oligonucleotide complex detection and Western blotting}

In two experiments, littermate animals were euthanized and dissected at $14 \mathrm{dpp}$, and testis lysates were prepared as described previously (Lange et al. 2011). In the third experiment, animals were nonlittermates but matched for age (14 dpp) and testis weight. Littermates are preferred controls, as their use minimizes experimental variability introduced by age and/or testis weight but can be challenging to obtain due to breeding constraints. SPO11-oligonucleotide complexes were isolated by two rounds of immunoprecipitation with a SPO11 monoclonal antibody (SPO11-180) on Protein A-agarose beads (Roche). SPO11oligonucleotide complexes were labeled with $\left[\alpha-{ }^{32} \mathrm{P}\right] \mathrm{dCTP}$ using terminal deoxynucleotidyl transferase (Fermentas), released from the beads by boiling in Laemmli buffer, and fractionated by SDSPAGE. The electrophoresed products were transferred onto polyvinylidene fluoride (PVDF) membrane. Radiolabeled species were detected using Fuji phosphor screens and quantified with ImageGauge software. Signals were quantified for $S_{p o 11^{+-}}$and $\mathrm{Tg}(\mathrm{Spo} 11 \beta)^{+/-}$testes and background-corrected by subtracting the signal from Spo11 ${ }^{-1-}$ testes. The same PVDF membrane was then subjected to Western analysis using the SPO11 monoclonal antibody, as described previously (Lange et al. 2011).

\section{Immunofluorescent detection of meiotic proteins}

Spermatocytes were prepared for surface spreading and processed using established methods (Peters et al. 1997; Barchi et al. 2008). Ovaries were collected from fetuses (15-20 d post-coitum) and newborn mice and processed to obtain oocyte chromosome spreads as previously described (de Boer et al. 2009). IF experiments were performed on spread meiotic chromosomes, and nuclei were staged as described previously (Roig et al. 2004; Barchi et al. 2008). For nucleus-wide RAD51 and DMC1 focus counts (Fig. 1B), we only considered $T g(S p o 11 \beta)^{+/-}$nuclei with normal-looking SYCP3 appearance; that is, no aberrant cell types were included. Only foci (RAD51, DMC1, and MLH1) colocalizing with SYCP3 staining were counted.

\section{FISH}

Prior to FISH experiments, IF was performed against SYCP3 to stage the meiotic nuclei. The FISH probes used were as follows: Star ${ }^{\star}$ FISH Cy3-conjugated chromosome 1 paint (Cambio), Star ${ }^{\star}$ FISH biotinylated chromosome 2 paint, Spectrum Greenlabeled (Vysis, Abbott Laboratories) DNA isolated from clone RP23-321L15 (chromosome 18), biotin-labeled DNA isolated from clone RP23-449B3 (chromosome 19), biotin-labeled DNA isolated from clone RP23-154O12 (X chromosome bacterial artificial chromosome [BAC]), Star^FISH FITC-conjugated X chromosome paint, and Star ${ }^{\star}$ FISH Cy3-conjugated Y chromosome paint.

Detailed FISH conditions were described previously (Kauppi et al. 2011). Briefly, after IF, slides were dehydrated and aged. FISH probes used in each experiment were combined in Star ${ }^{\star}$ FISH hybridization buffer in the presence of mouse Cot-1 DNA (Invitrogen). Slides were denatured for $7 \mathrm{~min}$ in $70 \%$ formamide and $0.6 \times \mathrm{SSC}$ at $72^{\circ} \mathrm{C}$. FISH was performed in a humid chamber for a minimum of $16 \mathrm{~h}$ at $37^{\circ} \mathrm{C}$. Slides were washed three times at $42^{\circ} \mathrm{C}$ in $4 \times$ SSC and $0.2 \%$ Tween-20. Biotin-labeled probes 
were detected using a Cy5-conjugated streptavidin secondary antibody (Amersham). Under the FISH conditions described here, most of the SYCP3 IF signal remains visible post-FISH.

\section{Analyses of RAD51 foci on unsynapsed chromosome axes}

IF was performed against SYCP3, SYCE2, and RAD51 on spread spermatocyte nuclei. Images of nuclei were captured using an Axio2 microscope (Zeiss) connected to a charge-coupled device camera and processed using SlideBook software (Intelligent Imaging Innovations). In SlideBook, the "Mask" function was used to select SYCP3-positive areas (all chromosome axes) and SYCE2positive areas (all synapsed axes) in the nucleus. The SYCE2 mask was subtracted from the SYCP3 mask to calculate the amount of unsynapsed axes (as number of pixels) in the nucleus. RAD51 foci were counted in each nucleus and classified as "on synapsed axes" or as "on unsynapsed axes."

To count the number of RAD51 foci on the obligately asynapsed portion of the $\mathrm{X}$ chromosome in wild-type mice, IF was performed with antibodies against RAD51 and SYCP3, and images of nuclei were captured; then, FISH was performed using the $\mathrm{X}$ chromosome BAC probe, and images of the same nuclei were captured post-FISH. This X chromosome BAC probe allowed us to identify the location of the pseudoautosomal boundary on the $\mathrm{X}$ chromosome axis. We then counted the number of RAD51 foci that colocalized with SYCP3 on the non-PAR portion of the $\mathrm{X}$ chromosome (the "PAR-proximal" axis) (Fig. 5D), taking into account only the $3.5-\mu \mathrm{m}$ stretch immediately adjacent to the FISH probe, or all of the axis marked by SYCP3 ("entire measurable" axis) (Fig. 5E). The distance of $3.5 \mu \mathrm{m}$ was chosen because it is a length that was informative in both early/mid- and late zygotene nuclei.

\section{Histology}

Ovaries and testes were dissected, fixed in $4 \%$ paraformaldehyde, and processed as described previously (Barchi et al. 2005; Di Giacomo et al. 2005). TUNEL staining to detect apoptotic cells in testis sections was performed as described (Baudat et al. 2000).

\section{Acknowledgments}

We thank Esther de Boer, Ignasi Roig, and Francesca Cole for valuable discussions and comments. Assistance provided by Raymond Wang and Jodi-Ann Sampson was instrumental in Spo11ß transgene genotyping. We are grateful to Michael P. Thelen, Ewelina Bolcun-Filas, Howard Cooke, Prasad Jallepalli, and Titia de Lange for sharing antibodies. Katia Manova and Yevgeniy Romin (Molecular Cytology Core Facility, MSKCC) provided assistance and advice with histology. This work was supported by NIH grant R01-GM105421 (to M.J. and S.K.). J.L. is supported by an American Cancer Society post-doctoral fellowship. M.B. is supported by Telethon Foundation (grant no. GGP12189) and the Ministry of Education, Universities, and Research of Italy (Cooperlink grant 2011 no. CII11RLETZ). F.B. is supported by the Centre National de la Recherche Scientifique (CNRS). S.K. is an Investigator of the Howard Hughes Medical Institute.

\section{References}

Ahmed EA, de Rooij DG. 2009. Staging of mouse seminiferous tubule cross-sections. Methods Mol Biol 558: 263-277.

Albini SM, Jones GH. 1984. Synaptonemal complex-associated centromeres and recombination nodules in plant meiocytes prepared by an improved surface-spreading technique. Exp Cell Res 155: 588-592.

Alpi A, Pasierbek P, Gartner A, Loidl J. 2003. Genetic and cytological characterization of the recombination protein RAD-51 in Caenorhabditis elegans. Chromosoma 112: 6-16.

Barchi M, Mahadevaiah S, Di Giacomo M, Baudat F, de Rooij DG, Burgoyne PS, Jasin M, Keeney S. 2005. Surveillance of different recombination defects in mouse spermatocytes yields distinct responses despite elimination at an identical developmental stage. Mol Cell Biol 25: 7203-7215.

Barchi M, Roig I, Di Giacomo M, de Rooij DG, Keeney S, Jasin M. 2008. ATM promotes the obligate XY crossover and both crossover control and chromosome axis integrity on autosomes. PLoS Genet 4: e1000076.

Barlow AL, Benson FE, West SC, Hulten MA. 1997. Distribution of the Rad51 recombinase in human and mouse spermatocytes. EMBO J 16: 5207-5215.

Baudat F, Manova K, Yuen JP, Jasin M, Keeney S. 2000. Chromosome synapsis defects and sexually dimorphic meiotic progression in mice lacking Spo11. Mol Cell 6: 989-998.

Bellani MA, Boateng KA, McLeod D, Camerini-Otero RD. 2010. The expression profile of the major mouse SPO11 isoforms indicates that SPO11 $\beta$ introduces double strand breaks and suggests that SPO1 $1 \alpha$ has an additional role in prophase in both spermatocytes and oocytes. Mol Cell Biol 30: 43914403.

Boateng KA, Bellani MA, Gregoretti IV, Pratto F, CameriniOtero RD. 2013. Homologous pairing preceding SPO11mediated double-strand breaks in mice. Dev Cell 24: 196205.

Bojko M. 1983. Human meiosis VIII. Chromosome pairing and formation of the synaptonemal complex in oocytes. Carlsberg Res Commun 48: 457-483.

Bolcun-Filas E, Costa Y, Speed R, Taggart M, Benavente R, De Rooij DG, Cooke HJ. 2007. SYCE2 is required for synaptonemal complex assembly, double strand break repair, and homologous recombination. J Cell Biol 176: 741-747.

Borodin PM, Gorlov IP, Agulnik AI, Agulnik SI, Ruvinsky AO. 1991. Chromosome pairing and recombination in mice heterozygous for different translocations in chromosomes 16 and 17. Chromosoma 101: 252-258.

Cha RS, Weiner BM, Keeney S, Dekker J, Kleckner N. 2000. Progression of meiotic DNA replication is modulated by interchromosomal interaction proteins, negatively by Spo11p and positively by Rec8p. Genes Dev 14: 493-503.

Chen SY, Tsubouchi T, Rockmill B, Sandler JS, Richards DR, Vader G, Hochwagen A, Roeder GS, Fung JC. 2008. Global analysis of the meiotic crossover landscape. Dev Cell 15: 401-415.

Cole F, Keeney S, Jasin M. 2010. Comprehensive, fine-scale dissection of homologous recombination outcomes at a hot spot in mouse meiosis. Mol Cell 39: 700-710.

Cole F, Kauppi L, Lange J, Roig I, Wang R, Keeney S, Jasin M. 2012. Homeostatic control of recombination is implemented progressively in mouse meiosis. Nat Cell Biol 14: 424-430.

Daniel K, Lange J, Hached K, Fu J, Anastassiadis K, Roig I, Cooke HJ, Stewart AF, Wassmann K, Jasin M, et al. 2011. Meiotic homologue alignment and its quality surveillance are controlled by mouse HORMAD1. Nat Cell Biol 13: 599-610.

Davis L, Barbera M, McDonnell A, McIntyre K, Sternglanz R, Jin Q, Loidl J, Engebrecht J. 2001. The Saccharomyces cerevisiae MUM2 gene interacts with the DNA replication machinery and is required for meiotic levels of double strand breaks. Genetics 157: 1179-1189.

de Boer P, Searle AG, van der Hoeven FA, de Rooij DG, Beechey CV. 1986. Male pachytene pairing in single and double 
translocation heterozygotes and spermatogenic impairment in the mouse. Chromosoma 93: 326-336.

de Boer E, Lhuissier FG, Heyting C. 2009. Cytological analysis of interference in mouse meiosis. Methods Mol Biol 558: 355382.

de Vries SS, Baart EB, Dekker M, Siezen A, de Rooij DG, de Boer $\mathrm{P}$, te Riele H. 1999. Mouse MutS-like protein Msh5 is required for proper chromosome synapsis in male and female meiosis. Genes Dev 13: 523-531.

de Vries FA, de Boer E, van den Bosch M, Baarends WM, Ooms M, Yuan L, Liu JG, van Zeeland AA, Heyting C, Pastink A. 2005. Mouse Sycp1 functions in synaptonemal complex assembly, meiotic recombination, and XY body formation. Genes Dev 19: 1376-1389.

Di Giacomo M, Barchi M, Baudat F, Edelmann W, Keeney S, Jasin M. 2005. Distinct DNA-damage-dependent and -independent responses drive the loss of oocytes in recombination-defective mouse mutants. Proc Natl Acad Sci 102: 737742.

Dix DJ, Allen JW, Collins BW, Poorman-Allen P, Mori C, Blizard DR, Brown PR, Goulding EH, Strong BD, Eddy EM. 1997. HSP70-2 is required for desynapsis of synaptonemal complexes during meiotic prophase in juvenile and adult mouse spermatocytes. Development 124: 4595-4603.

Eaker S, Cobb J, Pyle A, Handel MA. 2002. Meiotic prophase abnormalities and metaphase cell death in MLH1-deficient mouse spermatocytes: Insights into regulation of spermatogenic progress. Dev Biol 249: 85-95.

Edelmann W, Cohen PE, Kneitz B, Winand N, Lia M, Heyer J, Kolodner R, Pollard JW, Kucherlapati R. 1999. Mammalian MutS homologue 5 is required for chromosome pairing in meiosis. Nat Genet 21: 123-127.

Hayashi M, Chin GM, Villeneuve AM. 2007. C. elegans germ cells switch between distinct modes of double-strand break repair during meiotic prophase progression. PLoS Genet 3: e191.

Henderson KA, Keeney S. 2004. Tying synaptonemal complex initiation to the formation and programmed repair of DNA double-strand breaks. Proc Natl Acad Sci 101: 45194524.

Henderson KA, Keeney S. 2005. Synaptonemal complex formation: Where does it start? Bioessays 27: 995-998.

Henzel JV, Nabeshima K, Schvarzstein M, Turner BE, Villeneuve AM, Hillers KJ. 2011. An asymmetric chromosome pair undergoes synaptic adjustment and crossover redistribution during Caenorhabditis elegans meiosis: Implications for sex chromosome evolution. Genetics 187: 685-699.

Holm PB. 1978. Human meiosis III. Electron microscopical analysis of chromosome pairing in an individual with a balanced translocation 46, XY, $\mathrm{t}\left(5 \mathrm{p}^{-} ; 22 \mathrm{p}^{+}\right)$. Carlsberg Res Commun 43: 329-350.

Hunt PA, Hassold TJ. 2002. Sex matters in meiosis. Science 296: 2181-2183.

Hunter N. 2007. Meiotic recombination. In Molecular genetics of recombination (ed. Aguilera A Rothstein R), pp. 381-442. Springer-Verlag, Heidelberg, Germany.

Jang JK, Sherizen DE, Bhagat R, Manheim EA, McKim KS. 2003. Relationship of DNA double-strand breaks to synapsis in Drosophila. J Cell Sci 116: 3069-3077.

Joyce EF, Pedersen M, Tiong S, White-Brown SK, Paul A, Campbell SD, McKim KS. 2011. Drosophila ATM and ATR have distinct activities in the regulation of meiotic DNA damage and repair. I Cell Biol 195: 359-367.

Kauppi L, Barchi M, Baudat F, Romanienko PJ, Keeney S, Jasin M. 2011. Distinct properties of the XY pseudoautosomal region crucial for male meiosis. Science 331: 916-920.
Kauppi L, Jasin M, Keeney S. 2012. The tricky path to recombining X and Y chromosomes in meiosis. Ann N Y Acad Sci 1267: 18-23.

Keeney S, Baudat F, Angeles M, Zhou ZH, Copeland NG, Jenkins NA, Manova K, Jasin M. 1999. A mouse homolog of the Saccharomyces cerevisiae meiotic recombination DNA transesterase Spol1p. Genomics 61: 170-182.

Kleckner N. 1995. Interactions between and along chromosomes during meiosis. Harvey Lect 91: 21-45.

Kneitz B, Cohen PE, Avdievich E, Zhu L, Kane MF, Hou H Jr, Kolodner RD, Kucherlapati R, Pollard JW, Edelmann W. 2000. MutS homolog 4 localization to meiotic chromosomes is required for chromosome pairing during meiosis in male and female mice. Genes Dev 14: 1085-1097.

Lange J, Skaletsky H, van Daalen SK, Embry SL, Korver CM, Brown LG, Oates RD, Silber S, Repping S, Page DC. 2009. Isodicentric $\mathrm{Y}$ chromosomes and sex disorders as byproducts of homologous recombination that maintains palindromes. Cell 138: 855-869.

Lange J, Pan J, Cole F, Thelen MP, Jasin M, Keeney S. 2011. ATM controls meiotic double-strand-break formation. Nature 479: 237-240.

Lenzi ML, Smith J, Snowden T, Kim M, Fishel R, Poulos BK, Cohen PE. 2005. Extreme heterogeneity in the molecular events leading to the establishment of chiasmata during meiosis I in human oocytes. Am J Hum Genet 76: 112-127.

Maguire MP. 1984. The mechanism of meiotic homologue pairing. I Theor Biol 106: 605-615.

Mancera E, Bourgon R, Brozzi A, Huber W, Steinmetz LM. 2008. High-resolution mapping of meiotic crossovers and noncrossovers in yeast. Nature 454: 479-485.

Martini E, Diaz RL, Hunter N, Keeney S. 2006. Crossover homeostasis in yeast meiosis. Cell 126: 285-295.

McClintock B. 1933. The association of non-homologous parts of chromosomes in the mid-prophase of meiosis in Zea mays. Z Zellforsch Mikrosk Anat 19: 191-237.

Mets DG, Meyer BJ. 2009. Condensins regulate meiotic DNA break distribution, thus crossover frequency, by controlling chromosome structure. Cell 139: 73-86.

Milman N, Higuchi E, Smith GR. 2009. Meiotic DNA doublestrand break repair requires two nucleases, MRN and Ctp1, to produce a single size class of Rec12 (Spo11)-oligonucleotide complexes. Mol Cell Biol 29: 5998-6005.

Moens PB, Chen DJ, Shen Z, Kolas N, Tarsounas M, Heng HH, Spyropoulos B. 1997. Rad51 immunocytology in rat and mouse spermatocytes and oocytes. Chromosoma 106: 207215.

Moses MJ, Poorman PA. 1981. Synaptosomal complex analysis of mouse chromosomal rearrangements. II. Synaptic adjustment in a tandem duplication. Chromosoma 81: 519-535.

Moses MJ, Poorman PA, Roderick TH, Davisson MT. 1982. Synaptonemal complex analysis of mouse chromosomal rearrangements. IV. Synapsis and synaptic adjustment in two paracentric inversions. Chromosoma 84: 457-474.

Moses MJ, Dresser ME, Poorman PA. 1984. Composition and role of the synaptonemal complex. Symp Soc Exp Biol 38: 245-270.

Neale MJ, Pan J, Keeney S. 2005. Endonucleolytic processing of covalent protein-linked DNA double-strand breaks. Nature 436: $1053-1057$.

Oliver-Bonet M, Turek PJ, Sun F, Ko E, Martin RH. 2005. Temporal progression of recombination in human males. Mol Hum Reprod 11: 517-522.

Page J, de la Fuente R, Manterola M, Parra MT, Viera A, Berrios S, Fernandez-Donoso R, Rufas JS. 2012. Inactivation or nonreactivation: What accounts better for the silence of sex 
chromosomes during mammalian male meiosis? Chromosoma 121: 307-326.

Peoples-Holst TL, Burgess SM. 2005. Multiple branches of the meiotic recombination pathway contribute independently to homolog pairing and stable juxtaposition during meiosis in budding yeast. Genes Dev 19: 863-874.

Perry J, Palmer S, Gabriel A, Ashworth A. 2001. A short pseudoautosomal region in laboratory mice. Genome Res 11: 18261832.

Peters AH, Plug AW, van Vugt MJ, de Boer P. 1997. A dryingdown technique for the spreading of mammalian meiocytes from the male and female germline. Chromosome Res 5: 66-68.

Petukhova GV, Romanienko PJ, Camerini-Otero RD. 2003. The Hop2 protein has a direct role in promoting interhomolog interactions during mouse meiosis. Dev Cell 5: 927-936.

Pittman DL, Cobb J, Schimenti KJ, Wilson LA, Cooper DM, Brignull E, Handel MA, Schimenti JC. 1998. Meiotic prophase arrest with failure of chromosome synapsis in mice deficient for Dmc1, a germline-specific RecA homolog. Mol Cell 1: 697-705.

Plug AW, Xu J, Reddy G, Golub EI, Ashley T. 1996. Presynaptic association of Rad51 protein with selected sites in meiotic chromatin. Proc Natl Acad Sci 93: 5920-5924.

Plug AW, Peters AH, Keegan KS, Hoekstra MF, de Boer P, Ashley T. 1998. Changes in protein composition of meiotic nodules during mammalian meiosis. J Cell Sci 111: 413-423.

Qiao H, Chen JK, Reynolds A, Hoog C, Paddy M, Hunter N. 2012. Interplay between synaptonemal complex, homologous recombination, and centromeres during mammalian meiosis. PLoS Genet 8: e1002790.

Rasmussen SW, Holm PB. 1978. Human meiosis II. Chromosome pairing and recombination nodules in human spermatocytes. Carlsberg Res Commun 43: 275-327.

Rocco V, Nicolas A. 1996. Sensing of DNA non-homology lowers the initiation of meiotic recombination in yeast. Genes Cells 1: 645-661.

Roig I, Liebe B, Egozcue J, Cabero L, Garcia M, Scherthan H. 2004. Female-specific features of recombinational doublestranded DNA repair in relation to synapsis and telomere dynamics in human oocytes. Chromosoma 113: 22-33.

Roig I, Dowdle JA, Toth A, de Rooij DG, Jasin M, Keeney S. 2010. Mouse TRIP13/PCH2 is required for recombination and normal higher-order chromosome structure during meiosis. PLoS Genet 6: e1001062.

Romanienko PJ, Camerini-Otero RD. 1999. Cloning, characterization, and localization of mouse and human SPO11. Genomics 61: 156-169.

Romanienko PJ, Camerini-Otero RD. 2000. The mouse Spo11 gene is required for meiotic chromosome synapsis. Mol Cell 6: $975-987$.

Rosu S, Libuda DE, Villeneuve AM. 2011. Robust crossover assurance and regulated interhomolog access maintain meiotic crossover number. Science 334: 1286-1289.

Russell LD, Ettlin RA, Hikim APS, Clegg ED. 1990. Histological and histopathological evaluation of the testis, Cache River Press, Clearwater, FL.

Sanchez-Moran E, Santos JL, Jones GH, Franklin FC. 2007. ASY1 mediates AtDMC1-dependent interhomolog recombination during meiosis in Arabidopsis. Genes Dev 21: 22202233.

Sasaki M, Lange J, Keeney S. 2010. Genome destabilization by homologous recombination in the germ line. Nat Rev Mol Cell Biol 11: 182-195.

Sato A, Isaac B, Phillips CM, Rillo R, Carlton PM, Wynne DJ, Kasad RA, Dernburg AF. 2009. Cytoskeletal forces span the nuclear envelope to coordinate meiotic chromosome pairing and synapsis. Cell 139: 907-919.

Scherthan H, Weich S, Schwegler H, Heyting C, Harle M, Cremer T. 1996. Centromere and telomere movements during early meiotic prophase of mouse and man are associated with the onset of chromosome pairing. I Cell Biol 134: 11091125.

Shi Q, Spriggs E, Field LL, Ko E, Barclay L, Martin RH. 2001. Single sperm typing demonstrates that reduced recombination is associated with the production of aneuploid 24,XY human sperm. Am J Med Genet 99: 34-38.

Shin YH, Choi Y, Erdin SU, Yatsenko SA, Kloc M, Yang F, Wang PJ, Meistrich ML, Rajkovic A. 2010. Hormad1 mutation disrupts synaptonemal complex formation, recombination, and chromosome segregation in mammalian meiosis. PLOS Genet 6: e1001190.

Smithies O, Powers PA. 1986. Gene conversions and their relation to homologous chromosome pairing. Philos Trans $R$ Soc Lond B Biol Sci 312: 291-302.

Storlazzi A, Gargano S, Ruprich-Robert G, Falque M, David M, Kleckner N, Zickler D. 2010. Recombination proteins mediate meiotic spatial chromosome organization and pairing. Cell 141: 94-106.

Terasawa M, Shinohara A, Hotta Y, Ogawa H, Ogawa T. 1995. Localization of RecA-like recombination proteins on chromosomes of the lily at various meiotic stages. Genes Dev 9: 925-934.

Tesse S, Storlazzi A, Kleckner N, Gargano S, Zickler D. 2003. Localization and roles of Ski8p protein in Sordaria meiosis and delineation of three mechanistically distinct steps of meiotic homolog juxtaposition. Proc Natl Acad Sci 100: 12865-12870.

Tres LL. 1977. Extensive pairing of the XY bivalent in mouse spermatocytes as visualized by whole-mount electron microscopy. J Cell Sci 25: 1-15.

Vasco C, Manterola M, Page J, Zuccotti M, de la Fuente R, Redi CA, Fernandez-Donoso R, Garagna S. 2012. The frequency of heterologous synapsis increases with aging in Robertsonian heterozygous male mice. Chromosome Res 20: $269-278$.

von Wettstein D, Rasmussen SW, Holm PB. 1984. The synaptonemal complex in genetic segregation. Annu Rev Genet 18: 331-413.

Weiner BM, Kleckner N. 1994. Chromosome pairing via multiple interstitial interactions before and during meiosis in yeast. Cell 77: 977-991.

Wojtasz L, Daniel K, Roig I, Bolcun-Filas E, Xu H, Boonsanay V, Eckmann CR, Cooke HI, Jasin M, Keeney S, et al. 2009. Mouse HORMAD1 and HORMAD2, two conserved meiotic chromosomal proteins, are depleted from synapsed chromosome axes with the help of TRIP13 AAA-ATPase. PLOS Genet 5: e1000702.

Xu L, Kleckner N. 1995. Sequence non-specific double-strand breaks and interhomolog interactions prior to double-strand break formation at a meiotic recombination hot spot in yeast. EMBO J 14: 5115-5128.

Zhang L, Kleckner NE, Storlazzi A, Kim KP. 2011. Meiotic double-strand breaks occur once per pair of (sister) chromatids and, via Mecl/ATR and Tell/ATM, once per quartet of chromatids. Proc Natl Acad Sci 108: 20036-20041.

Zickler D. 1977. Development of the synaptonemal complex and the 'recombination nodules' during meiotic prophase in the seven bivalents of the fungus Sordaria macrospora Auersw. Chromosoma 61: 289-316.

Zickler D, Kleckner N. 1999. Meiotic chromosomes: Integrating structure and function. Annu Rev Genet 33: 603-754. 


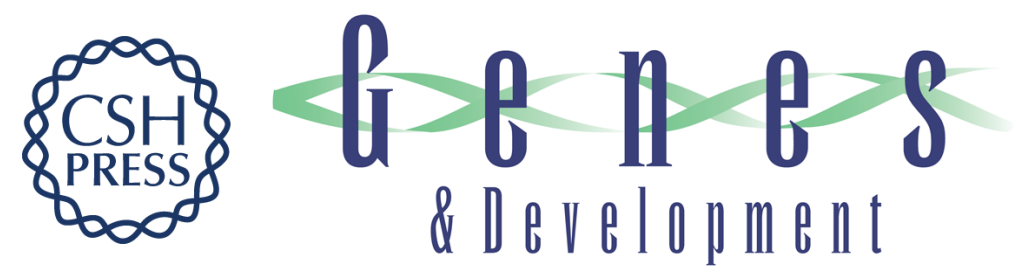

\section{Numerical constraints and feedback control of double-strand breaks in mouse meiosis}

Liisa Kauppi, Marco Barchi, Julian Lange, et al.

Genes Dev. 2013, 27: originally published online April 18, 2013

Access the most recent version at doi:10.1101/gad.213652.113

\section{Supplemental http://genesdev.cshlp.org/content/suppl/2013/04/11/gad.213652.113.DC1 Material}

References This article cites 89 articles, 29 of which can be accessed free at: http://genesdev.cshlp.org/content/27/8/873.full.html\#ref-list-1

\section{License}

Email Alerting

Receive free email alerts when new articles cite this article - sign up in the box at the top Service 